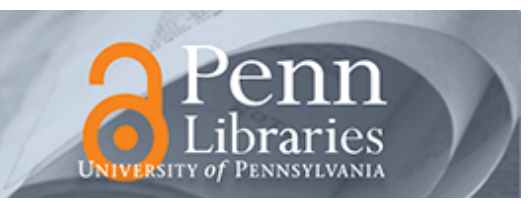

University of Pennsylvania ScholarlyCommons

January 1999

\title{
The Differential Impacts of Federally Assisted Housing Programs on Nearby Property Values: A Philadelphia Case Study
}

Chang-Moo Lee

University of Pennsylvania

Dennis P. Culhane

University of Pennsylvania, culhane@upenn.edu

Susan M. Wachter

University of Pennsylvania, wachter@wharton.upenn.edu

Follow this and additional works at: https://repository.upenn.edu/spp_papers

\section{Recommended Citation}

Lee, C., Culhane, D. P., \& Wachter, S. M. (1999). The Differential Impacts of Federally Assisted Housing Programs on Nearby Property Values: A Philadelphia Case Study. Retrieved from https://repository.upenn.edu/spp_papers/64

Reprinted from Housing Policy Debate, Volume 10, Issue 2, 1999, pages 75-93.

We have contacted the publisher regarding the deposit of this paper in ScholarlyCommons@Penn. No response has been received.

This paper is posted at ScholarlyCommons. https://repository.upenn.edu/spp_papers/64

For more information, please contact repository@pobox.upenn.edu. 


\title{
The Differential Impacts of Federally Assisted Housing Programs on Nearby Property Values: A Philadelphia Case Study
}

\begin{abstract}
Prior research has found negative impacts of public housing on neighborhood quality. Few studies have examined the impact of public and other assisted housing programs on real estate prices, particularly differential impact by program type. In this study, federally assisted housing units by program type are aggregated by $1 / 8$ - or 1/4-mile radii around individual property sales and regressed on sales prices from 1989 through 1991, controlling for area demographic, housing, and amenity variables.

Results show that public housing developments exert a modest negative impact on property values. Scattered-site public housing and units rented with Section 8 certificates and vouchers have slight negative impacts. Federal Housing Administration-assisted units, public housing homeownership program units, and Section 8 New Construction and Rehabilitation units have modest positive impacts. Low-Income Housing Tax Credit sites have a slight negative effect. Results suggest that homeownership programs and new construction/rehabilitation programs have a more positive impact on property values.
\end{abstract}

\section{Keywords}

assisted housing, public housing, property values, positive impact

\section{Comments}

Reprinted from Housing Policy Debate, Volume 10, Issue 2, 1999, pages 75-93.

We have contacted the publisher regarding the deposit of this paper in ScholarlyCommons@Penn. No response has been received. 
(c) Fannie Mae Foundation 1999. All Rights Reserved.

\title{
The Differential Impacts of Federally Assisted Housing Programs on Nearby Property Values: A Philadelphia Case Study
}

\author{
Chang-Moo Lee, Dennis P. Culhane, and Susan M. Wachter \\ University of Pennsylvania
}

\begin{abstract}
Prior research has found negative impacts of public housing on neighborhood quality. Few studies have examined the impact of public and other assisted housing programs on real estate prices, particularly differential impact by program type. In this study, federally assisted housing units by program type are aggregated by 1/8- or 1/4-mile radii around individual property sales and regressed on sales prices from 1989 through 1991, controlling for area demographic, housing, and amenity variables.

Results show that public housing developments exert a modest negative impact on property values. Scattered-site public housing and units rented with Section 8 certificates and vouchers have slight negative impacts. Federal Housing Administration-assisted units, public housing homeownership program units, and Section 8 New Construction and Rehabilitation units have modest positive impacts. Low-Income Housing Tax Credit sites have a slight negative effect. Results suggest that homeownership programs and new construction/rehabilitation programs have a more positive impact on property values.
\end{abstract}

Keywords: Assisted housing; Public housing; Property values

\section{Introduction}

Federally assisted housing programs, particularly public housing developments, have been associated with negative neighborhood impacts by a number of investigators (Carter, Schill, and Wachter 1998; Newman and Schnare 1997; Schill and Wachter 1995). To date, much of the literature has focused on public housing's effects on racial segregation and poverty concentration, while few studies have examined its impact on real estate prices. As a result of court orders and various policy initiatives, other rental assistance programs have attempted to counteract segregation and poverty concentrations by providing for greater social and geographic mobility of assisted housing recipients or by modifying siting procedures for public housing. Still other programs have attempted to assist lowincome households to attain homeownership rather than merely providing rental housing. 
Tenant-based certificates, mobility programs, scattered-site developments, and homeownership programs are anticipated to produce better locational outcomes for assisted households than traditional public housing developments. One might expect that such alternative programs would be associated with fewer negative neighborhood effects, including impacts on real estate prices, but it is also possible that owing to real or perceived problems associated with poor households' spatial concentration, any housing assistance aimed at them might be seen as a bad influence on the neighborhood and its value on the real estate market. Using Philadelphia as the locus for a case study, this article examines the differential effects of federally assisted housing programs by type on real estate prices.

\section{Literature review}

\section{Assisted housing and neighborhood characteristics}

Several researchers have associated public housing developments with negative neighborhood impacts, particularly racial segregation and poverty concentration. Such impacts have concerned researchers and policy makers because they undermine one of the key objectives of housing assistance programs, namely, to provide for the "suitable living environment" prescribed by the 1949 Housing Act (Newman and Schnare 1997). By contributing to, rather than ameliorating, the troubled neighborhood conditions in which many poor families live, public housing developments may also contribute to their residents' reduced economic mobility and to social problems believed to promote persistent poverty, including reduced rates of household formation, delinquency, poor educational attainment, and low levels of labor force participation. Indeed, a literature has emerged that links poor neighborhood conditions with belowaverage school achievement (Aaronson 1995) and high rates of youth unemployment (Wilson 1987) and crime and delinquency (Wilson and Kelling 1982). According to Newman and Schnare, however, it is not yet clear "what features of a neighborhood matter, for whom, and under what conditions" (1997, 705).

Whether or not assisted housing programs contribute to such effects is of critical concern, particularly as they and welfare programs are being refashioned with the partial goal of improving the economic self-sufficiency of recipients. Even prior to the most recent changes, shifts in housing policy have tacitly acknowledged the poor locational outcomes of public housing developments by promoting either geographic mobility or placement of housing developments in more heterogeneous neighborhoods. Thus, although public housing developments, particularly older sites, were often located in such a way 
as to reinforce race and poverty concentrations (Schill and Wachter 1995), more recent initiatives have been developed specifically to reduce the likelihood of such effects. Programs resulting from litigation (for example, the Gautreaux program), tenant-based certificates and vouchers, the Moving to Opportunity program, and even, to some extent, scattered-site public housing developments were designed either to increase the geographic mobility of residents or to reduce the likelihood that residents would live in high-poverty areas.

The differential effects of this broader spectrum of programs on neighborhood quality have only recently begun to be examined. The literature currently being developed will probably produce a more textured profile of assisted housing programs and their effects than have studies of public housing developments alone. In the most significant effort to date, Newman and Schnare (1997) compare the locations of public housing developments, publicly financed private developments, housing occupied by recipients of certificates and vouchers, and all other rental housing, including welfare recipients' housing, finding significant variations in neighborhood quality by program type. Using national data, the authors examine the differential association of housing assistance programs with neighborhood income, the poverty rate, the employment rate, the minority concentration rate, rents, and the density of assisted housing households. They also investigate differences in neighborhood attributes within public housing programs and within the publicly assisted private stock.

The authors conclude that both public and private project-based housing assistance programs do little to improve neighborhood quality for welfare recipients. Indeed, Newman and Schnare find that the neighborhood characteristics of public housing developments for families were worse than for the welfare population overall and that such housing fostered, rather than reduced, economic and racial segregation. This effect was "widespread" and "cannot be attributed to only a small proportion of seriously distressed developments" (1997, 727). The association between racial isolation and public housing location was particularly prominent among the larger public housing developments (those with more than 2,500 units). The stock of publicly assisted, privately owned developments was not located in areas substantially different from those of the public assistance population overall and so did not improve their locational outcomes-although it did not worsen their relative locations, either. However, the authors report evidence that certificate and voucher programs reduce the likelihood that families live in troubled neighborhoods. Although they do not move to middle- and upper-income areas, certificate and voucher recipients do not live in 
the most distressed neighborhoods and experience improvement in location relative to that of the welfare population overall.

As to whether public housing developments are the cause of the observed neighborhood characteristics or whether public housing developments are sited in distressed areas or areas likely to become distressed, Newman and Schnare argue the latter. According to them, public housing is unlikely to be responsible for the characteristics of the neighborhood given its relatively low proportion in comparison with other forms of housing in most tracts. They also cite historical evidence to affirm that neighborhood decline had already taken place or was beginning before most public housing developments were sited (Schill and Wachter 1995). However, Newman and Schnare's results also show that for as many as 28 percent of the public housing developments, assisted housing accounts for more than 50 percent of the housing stock in the census tract. Thus, particularly in the case of large developments, it is possible that by size alone, public housing may well become the defining characteristic of an area, leading to or exacerbating neighborhood decline. Moreover, from an intertemporal perspective, public housing development locations have been found to be associated with later, further concentrations of minority and poor households (Carter, Schill, and Wachter 1998; Schill and Wachter 1995). Although some trends of distress may merely be exacerbated by siting decisions, the possibility of diffusion effects of public housing cannot be ruled out. To the extent that other forms of assisted housing may also be associated, presumably more modestly, with distressed neighborhood characteristics, the possibility of clustering or diffusion effects also cannot be eliminated. However, their much smaller scale relative to large public housing developments seems to make such effects less probable and the siting explanation more tenable.

\section{Assisted housing and property values}

The relationship of assisted housing to yet another neighborhood characteristic, its real estate market's relative strength, was not included in Newman and Schnare's national study. Indeed, only a few studies-three from 25 or more years ago-have assessed the impact of assisted housing on property values (Chandler, Benson, and Klein 1993; DeSalvo 1974; Galster and Tatian 1998; Guy, Hysom, and Ruth 1985; Nourse 1963; Rabiega, Lin, and Robinson 1984; Schafer 1972). Nourse (1963), studying "urban renewal" (the replacement of dilapidated housing with multifamily public housing) in St. Louis, finds no effect of public housing on real estate prices in the intervention areas compared with control neighborhoods. Schafer (1972) similarly finds no effect of Below Market Interest Rate (BMIR) rehabilitation loan program-funded projects on adja- 
cent properties in Los Angeles, though it was hypothesized that the introduction of low-income minority households would contribute to so-called white flight and a concomitant drop in property values in the mostly middle-income areas in which they were sited. DeSalvo (1974), studying the impact of the Mitchell-Lama projects in New York City, notes that property values in the intervention areas increased at twice the annual rate of property values in control areas and that the effect was greater in lower-rent than higher-rent areas.

Among the more recent studies, Rabiega, Lin, and Robinson (1984) report a small increase in property values at two varying distances from public housing developments (low- and medium-rise town houses) in Portland, Oregon. The property value increases were greatest for the zones farthest away from the public housing developments, suggesting that proximity to the public housing did have a suppressive effect. The authors qualify the results by noting the uniqueness of the Portland area, in which public housing developments were sited in relatively low- to moderate-density urban areas, were small in scale by national standards, served primarily a white population, and thus did not alter the perceived ethnic composition of the neighborhoods. A study by Guy, Hysom, and Ruth (1985) of subsidized (BMIR) developments concludes that "subsidized housing had a negative impact on the values of adjacent properties" (p. 378) based on a positive coefficient for the variable for distance from subsidized housing in a regression model predicting sales price. It is not clear from this analysis that property values declined, although proximity to subsidized housing was associated with suppressed value increases. Chandler, Benson, and Klein (1993) examine the impact in Cleveland of the Acquisition Housing Program (AHP), a scattered-site public housing initiative. The authors measure changes in the price-to-market value ratio based on a ratio of actual transfer value to an expected market value, derived from tax assessments, before and after the siting of AHP housing. The results indicate a positive market impact in 8 of 12 census tracts, with no change in 3 of the tracts. The authors did not employ a multivariate research design and so did not control for potential mediating variables.

Another recent analysis, by Galster and Tatian (1998), examines the impact of the concentration of Section 8 certificate and voucher units on nearby property values in Baltimore County at varying proximities. The authors found that within a 500-foot ring of sales, lower concentrations of Section 8 units are associated with positive effects on property values. However, larger concentrations of units, either within $500,1,000$, or 2,000 feet of sales and particularly within the 500-foot ring, are associated with negative impacts on value. The authors were able to include several important 
statistical controls for temporal, spatial, and neighborhood effects, providing a more carefully specified model than in previous research.

As a group, this body of research represents a relatively modest attempt to understand the impact of assisted housing programs on the real estate market. With the exception of the Galster and Tatian (1998) study, this research has employed limited statistical controls for neighborhood attributes or for existing trends in neighborhood conditions. ${ }^{1}$ Moreover, the studies are few in number, are limited in geographic scope, and span four decades, which precludes any general conclusions being drawn from them. Finally, each study focuses on a different type of assisted housing program in a different geographic area, prohibiting comparisons among types of assisted housing programs or even within a single program across jurisdictions.

\section{Study rationale}

Our study was designed to augment the literature by offering a comparative framework for assessing the relative impacts of various assisted housing program types-similar to the types of programs analyzed by Newman and Schnare (1997)—on property values. The study uses Philadelphia as its locus, limiting the degree to which its results could be generalized nationally. However, this strategy was selected to improve the feasibility of a parcel-level analysis of sales activity. In doing so, we could more readily take advantage of geographic information systems (GIS) analysis techniques that enable aggregation of assisted housing programs and program types by specified distances from property sales. These techniques also allow for the creation of spatial variables that can control for neighborhood characteristics, which might otherwise bias regression estimates (Bailey 1995). The study employs a hedonic rather than a repeat-sales indexing approach because too few repeated observations existed in the study period for which both sales data and neighborhood characteristic data were available (1989 through 1991). A pre-post design was not feasible, given that too few public

\footnotetext{
${ }^{1}$ Alternatively, studies of property value impacts of new housing construction or rehabilitation and of group homes or other supported living environments, while not shedding light on the impact of specific federally assisted housing programs, do provide additional references for research design and analytic approaches in this area. A study by Galster and Williams (1994) used hedonic price models to examine the impact of community housing for people with mental disabilities on property values, finding mixed effects of six such developments. Simons, Quercia, and Maric (1998) similarly employed a hedonic regression approach to estimate the impact of new housing construction on nearby property values, finding positive price impacts in one- to two-block areas, controlling for housing and neighborhood factors, that persisted for two years.
} 
housing developments were created after 1980, limiting a comparative assessment by program type.

\section{Hypotheses}

The poverty concentration associated with public housing developments (Schill and Wachter 1995) leads us to believe that these will have a more consistently negative association with property values. An additional negative effect is expected for larger developments, including high-rises, although it might diminish with distance. Increasing concentrations of scattered-site public housing units are probably also linked with negative impacts on property values. Public housing built since 1980 may lower surrounding property values more than public housing built before then as a result of the institution of federal "preferences" promulgated in 1980, which gave higher priority to poorer tenants for public housing vacancies, and Section 8 certificates. ${ }^{2}$ Publicly financed, private developments (Low-Income Housing Tax Credit [LIHTC] and Section 8 New Construction and Rehabilitation units) are unlikely to have significant impacts on property values, as the national data suggest that such programs are not associated with improved (or worsened) neighborhood characteristics (Newman and Schnare 1997). Certificate and voucher programs are expected to have a negative impact on value, as indicated in the results from the study of the Section 8 program's impact in Baltimore (Galster and Tatian 1998). Homeownership assistance program units (Federal Housing Administration [FHA] and the Philadelphia Housing Authority's [PHA's] homeownership program) are predicted to have a positive effect on property values because homeownership creates greater incentives for residents to improve the value of their properties than do the rental assistance programs.

\section{Methods}

\section{Data sources}

Assisted housing program data by address (FHA housing, LIHTC, Section 8 New Construction and Rehabilitation, and Section 8 certificates and vouchers) were obtained from the U.S. Department of

\footnotetext{
${ }^{2}$ Since 1980, the homeless, those paying more than 50 percent of income for rent, and those displaced from or living in substandard housing have been given greater priority for placement in public housing (Epp 1996), increasing the probability that new facilities will have higher concentrations of poor households. The Quality Housing and Work Responsibility Act of 1998 requires greater income mixing, allows targeting of higher-income tenants, and repeals federal preferences.
} 
Housing and Urban Development (HUD) for pre-1989 locations, including survey data published on the HUD Web site (HUD 1997). Detailed information on public housing development locations and characteristics, as well as scattered-site public housing locations, was obtained from the Philadelphia Planning Commission. All locational data were geocoded using GIS; locational variables were calculated using spatial analysis techniques in GIS and SAS software. Neighborhood condition variables at the census block group level were abstracted from the 1990 Census Summary Tape Files 1A and $3 \mathrm{~A}$.

The sale price data and property-specific attribute data were obtained from the Board of Revision of Taxes in Philadelphia. Sales time was restricted to the period from 1989 through 1991 to correspond as closely as possible with the 1990 census data while retaining sufficient observations for the analysis. Only single-family residential property sales data, excluding condominiums, were abstracted. Address data for sales and property information were geocoded using address-matching procedures in a GIS. After the data were cleaned, a total of 18,062 sales were included in the final data set.

\section{Model and variables}

The empirical model assumes that property value is a function of property-specific attributes, period of sale, neighborhood quality, macrolocational amenities, and existence and programs characteristics of assisted housing in proximal areas. The variables for the analysis are listed in table 1 , and the descriptive statistics for the model variables are shown in table 2 .

Property characteristics for sale properties (property control variables) include lot size (square footage), living area (square footage), house type (dummy variables for semidetached and row house), garage (dummy), masonry (dummy), and stone (dummy). Sale period control variables include year of sale (dummy variables for 1990 and 1991) and season of sale (dummy variables for winter, spring, and summer). Neighborhood quality variables (control variables) at the block group level include percent black, percent Hispanic, percent unemployed, percent below poverty level, median household income, and percent boarded-up units. Macrolocational amenity variables (also control variables) include distance from central business district $(\mathrm{CBD})$ and dummy variables for living within 1/4, 1/2, or 1 mile of a park or river.

The housing programs included in the analysis are public housing developments, public housing scattered sites, FHA housing, 
Table 1. Model Variables

\begin{tabular}{|c|c|}
\hline Variable Name & Variable Definition \\
\hline SALEPRI & Property sales price \\
\hline LSQFTLOT & Lot size in log of square feet \\
\hline LSQFTLIV & Living area in log of square feet \\
\hline SEMIDETA & Dummy variable for semidetached housing \\
\hline ROWHOUSE & Dummy variable for row house \\
\hline GARAGE & Dummy variable for garage \\
\hline ONESTR & Dummy variable for one-story building \\
\hline MASONRY & Dummy variable for masonry \\
\hline STONE & Dummy variable for stone \\
\hline D90 & Dummy variable for year 1990 \\
\hline D91 & Dummy variable for year 1991 \\
\hline WINTER & Dummy variable for winter \\
\hline SPRING & Dummy variable for spring \\
\hline SUMMER & Dummy variable for summer \\
\hline PTBLACK & Percent of black residents \\
\hline PTHISPA & Percent of Hispanic residents \\
\hline PTUNEMP & Percent of unemployment rate among residents \\
\hline PTPOV & Percent of residents below poverty level \\
\hline MEDINC & Median household income \\
\hline PTBDUP & Percent of boarded-up units \\
\hline MEDYRSTR & Median year structure built \\
\hline LDISTCBD & Distance from CBD in log of miles \\
\hline DPRK0250 & Dummy variable for distance within $1 / 4$ mile from park and river \\
\hline DPRK0500 & Dummy variable for distance within $1 / 2$ mile from park and river \\
\hline DPRK1000 & Dummy variable for distance within 1 mile from park and river \\
\hline DPHIGH1 & $\begin{array}{l}\text { Dummy variable for high-rise public housing development } \\
\text { within } 1 / 8 \text { mile }\end{array}$ \\
\hline DPLARGE1 & $\begin{array}{l}\text { Dummy variable for large-scale public housing development } \\
\text { within } 1 / 8 \text { mile }\end{array}$ \\
\hline DPHOME1 & $\begin{array}{l}\text { Dummy variable for homeownership public housing development } \\
\text { within } 1 / 8 \text { mile }\end{array}$ \\
\hline D80P1 & $\begin{array}{l}\text { Dummy variable for public housing development built after } 1980 \\
\text { within } 1 / 8 \text { mile }\end{array}$ \\
\hline DPHIGH2 & $\begin{array}{l}\text { Dummy variable for high-rise public housing development } \\
\text { within } 1 / 4 \text { mile }\end{array}$ \\
\hline DPLARGE2 & $\begin{array}{l}\text { Dummy variable for large-scale public housing development } \\
\text { within } 1 / 4 \text { mile }\end{array}$ \\
\hline DPHOME2 & $\begin{array}{l}\text { Dummy variable for homeownership public housing development } \\
\text { within } 1 / 4 \text { mile }\end{array}$ \\
\hline D80P2 & $\begin{array}{l}\text { Dummy variable for public housing development built after } 1980 \\
\text { within } 1 / 4 \text { mile }\end{array}$ \\
\hline DOPUB125 & Dummy variable for public housing development within $1 / 8$-mile radius \\
\hline DPUB250 & Dummy variable for public housing development within $1 / 4$-mile radius \\
\hline DOPUB250 & $\begin{array}{l}\text { Dummy variable for public housing development within } 1 / 4 \text {-mile radius, } \\
\text { excluding those within } 1 / 8 \text {-mile radius }\end{array}$ \\
\hline NUSCA250 & Total number of scattered-site housing units within $1 / 4$-mile radius \\
\hline NUFHA250 & Total number of FHA-assisted housing units within 1/4-mile radius \\
\hline NUS8N250 & $\begin{array}{l}\text { Total number of Section } 8 \text { New Construction and Rehabilitation units } \\
\text { within 1/4-mile radius }\end{array}$ \\
\hline NUS8C250 & $\begin{array}{l}\text { Total number of Section } 8 \text { certificate and voucher units } \\
\text { within 1/4-mile radius }\end{array}$ \\
\hline NULTC250 & Total number of LIHTC housing units within $1 / 4$-mile radius \\
\hline
\end{tabular}


Table 2. Sample Statistics

\begin{tabular}{|c|c|c|}
\hline Variable & Mean & Standard Deviation \\
\hline SALEPRI & 47626.38 & 39811.84 \\
\hline LSQFTLOT & 7.24 & 0.619 \\
\hline LSQFTLIV & 7.099 & 0.285 \\
\hline SEMIDETA & 0.143 & 0.351 \\
\hline ROWHOUSE & 0.812 & 0.391 \\
\hline GARAGE & 0.432 & 0.495 \\
\hline ONESTR & 0.062 & 0.241 \\
\hline MASONRY & 0.925 & 0.263 \\
\hline STONE & 0.014 & 0.116 \\
\hline D90 & 0.337 & 0.473 \\
\hline D91 & 0.344 & 0.475 \\
\hline WINTER & 0.226 & 0.418 \\
\hline SPRING & 0.227 & 0.419 \\
\hline SUMMER & 0.262 & 0.44 \\
\hline PTBLACK & 30.192 & 39.695 \\
\hline PTHISPA & 6.666 & 15.438 \\
\hline PTUNEMP & 10.462 & 10.329 \\
\hline PTPOV & 18.418 & 15.458 \\
\hline MEDINC & 26129.04 & 9905.61 \\
\hline PTBDUP & 1.746 & 3.033 \\
\hline MEDYRSTR & 1944.65 & 9.261 \\
\hline LDISTCBD & 1.56 & 0.639 \\
\hline DPRK0250 & 0.046 & 0.209 \\
\hline DPRK0500 & 0.106 & 0.308 \\
\hline DPRK1000 & 0.239 & 0.427 \\
\hline DPHIGH1 & 0.001 & 0.027 \\
\hline DPLARGE1 & 0.000 & 0.013 \\
\hline DPHOME1 & 0.001 & 0.039 \\
\hline D80P1 & 0.002 & 0.043 \\
\hline DPHIGH2 & 0.005 & 0.07 \\
\hline DPLARGE2 & 0.001 & 0.032 \\
\hline DPHOME2 & 0.004 & 0.065 \\
\hline D80P2 & 0.005 & 0.072 \\
\hline DOPUB125 & 0.014 & 0.117 \\
\hline DPUB250 & 0.065 & 0.247 \\
\hline DOPUB250 & 0.052 & 0.221 \\
\hline NUSCA250 & 13.101 & 36.187 \\
\hline NUFHA250 & 2.143 & 17.761 \\
\hline NUS8N250 & 8.726 & 41.026 \\
\hline NUS8C250 & 11.968 & 13.576 \\
\hline NULTC250 & 4.602 & 18.706 \\
\hline
\end{tabular}

Section 8 New Construction and Rehabilitation, Section 8 certificates and vouchers, and LIHTC. Public housing developments are further differentiated by building type (high-rise, low-rise), program type (family, senior, homeownership), size of development (large or small), and era (built before or after 1980). Each property sale has radii of 1/8 and 1/4 miles drawn around it, and for each sale property, a dummy variable is created indicating whether a public housing development is located in the perimeter of a given zone by type 
(high-rise, large, homeownership, built after 1980). Similarly, the total number of scattered-site, FHA, Section 8 New Construction and Rehabilitation, Section 8 certificate and voucher, and LIHTC program units within a $1 / 4$-mile radius of the sale properties are aggregated by program per sale property.

The first model specification (Model I) tests the impacts of several types of assisted housing, including public housing developments (DOPUB125 and DOPUB250) either within 1/8 mile of the sale property or between $1 / 8$ and $1 / 4$ mile of the sale property, public housing scattered-site units (NUSCA250) aggregated within 1/4 mile of the sale, FHA housing units (NUFHA250) aggregated within 1/4 mile of the sale, Section 8 New Construction and Rehabilitation units (NUS8N250) aggregated within 1/4 mile of the sale, Section 8 certificate and voucher units (NUS8C250) aggregated within $1 / 4$ mile of the sale, and LIHTC units (NULTC250) aggregated within 1/4 mile of the sale. ${ }^{3}$ Model I does not include the neighborhood quality control variables or variables for the types of public housing developments. The second model specification adds the neighborhood control variables (Model II) to the variables used in Model I. In Model III, more detailed characteristics of public housing developments are introduced to examine the heterogeneous impacts of building and program types. These include DPHIGH (a dummy for high-rise developments), DPLARGE (a dummy for largescale developments), DPHOME (a dummy for PHA's homeownership programs), and D80P2 (a dummy for public housing developments built after 1980). All of these variables are calculated using a 1/4-mile criterion. The final model specification (Model IV) differs from Model III in that it tests for the effect of public housing developments within 1/8 mile versus $1 / 4$ mile. This is done to apply a stricter distance criterion, which would presumably be more sensitive to negative price effects, particularly as they may vary by types of public housing developments.

\section{Results}

\section{Control variables}

Among the property-specific control variables, all except MASONRY produce positive coefficients at a statistically significant level (see

\footnotetext{
${ }^{3}$ Within the original data set, the authors deleted the observations with notable coding errors (out-of-range codes), notable outliers based on the sample statistics of each variable, and the residual plot. Also, the residual plot test for three different functional forms-linear, full-log, and semi-log models-was carried out and showed that the semi-log model was the most acceptable functional form in terms of shape and variability.
} 
table 3). ${ }^{4}$ Masonry is the most common building material of houses in Philadelphia, particularly among the city's many older row houses. Although MASONRY produces a negative coefficient in Model I, it becomes positive in the other two models when the neighborhood characteristics variables are included (see table 3). Also, the insignificant positive coefficient of STONE in Model I increases in magnitude and becomes statistically significant in the other models when neighborhood quality variables are introduced. This indicates that a premium for endurable materials exists in spite of building age and location. The estimation results show some yearly fluctuations for the year-of-sale control variables, but they are only marginally significant. For the seasonal impacts, the estimation results indicate that negative impacts exist on sales in winter and spring; for summer, the estimated coefficient is not significant. All of the neighborhood quality control variables obtain expected signs at statistically significant levels throughout the model variations. The macrolocational amenity variable for distance to the central business district (LDISTCBD) produces an expected negative coefficient (positive effect of accessibility) and is statistically significant. The dummy variables for park and river accessibility produce statistically significant positive coefficients, decreasing in magnitude by distance.

\section{Assisted housing variables}

The coefficients for the two dummy variables in Model I for distance from public housing developments (DOPUB125 and DOPUB250) show that the impact of public housing developments reduces by distance $(-0.4$ for $1 / 8$ mile to -0.2 for $1 / 4$ mile). For other types of assisted housing, the number of units for each program within $1 / 4$ mile from the sale property location is used. All types of assisted housing programs, except FHA housing, have negative impacts on property values in nearby areas, and their coefficients are statistically significant. The variables for public housing developments (DOPUB125 and DOPUB250) and Section 8 New Construction and Rehabilitation units (NUS8N250) have the largest negative coefficients.

However, when neighborhood quality variables (the spatial control variables) are included in Model II, the $R^{2}$ increases considerably (from 0.55 to 0.72 ), and the coefficients of the variables are reduced considerably in magnitude or change in sign. For example, DOPUB125, the measure reflecting a 1/8-mile distance from

\footnotetext{
${ }^{4}$ It is noteworthy that SEMIDETA and ROWHOUSE become negative when LSQFTLOT is dropped. This indicates that the premium for a single-family detached house is based on the lot size.
} 
The Differential Impacts of Federally Assisted Housing Programs

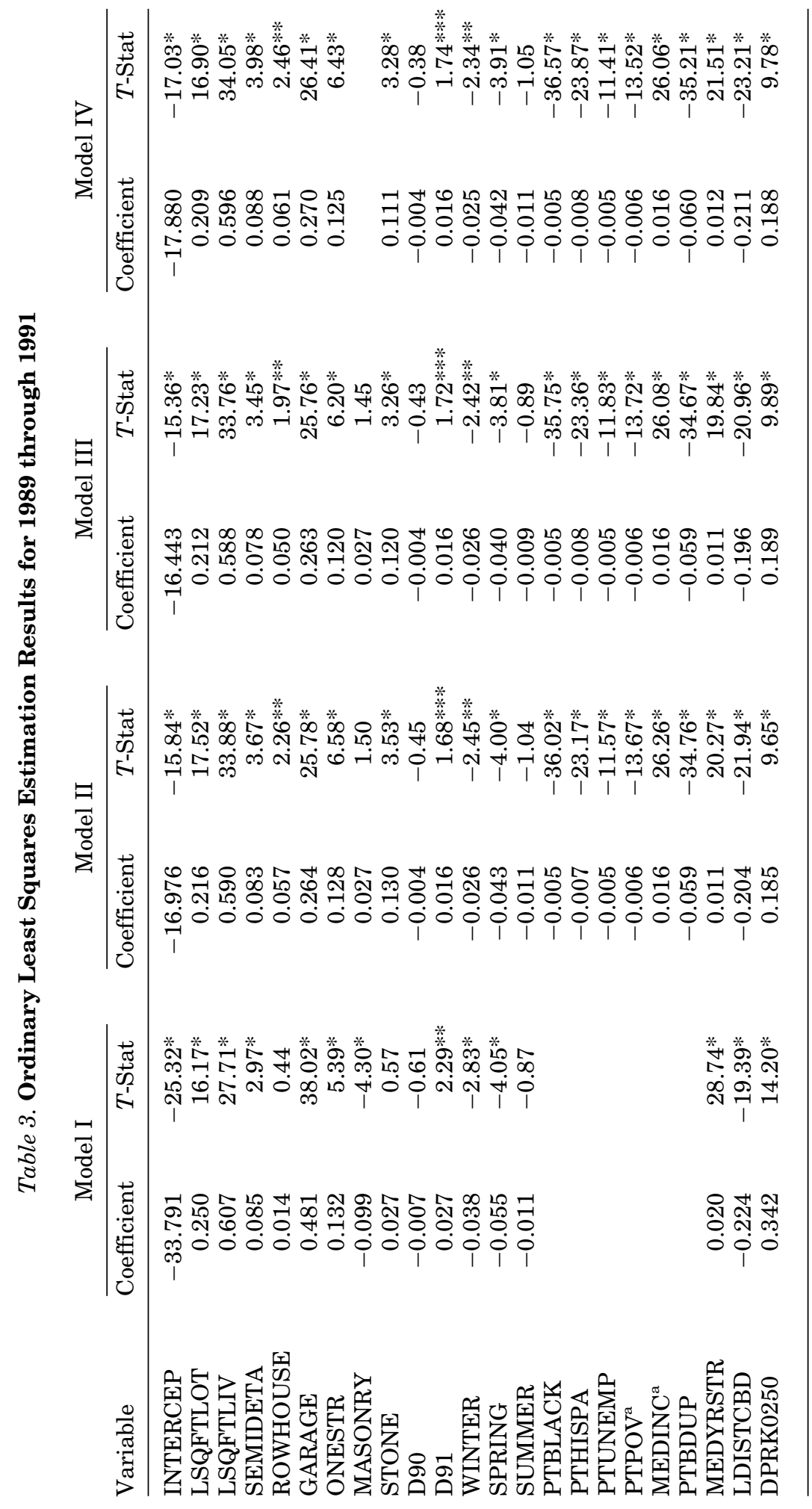




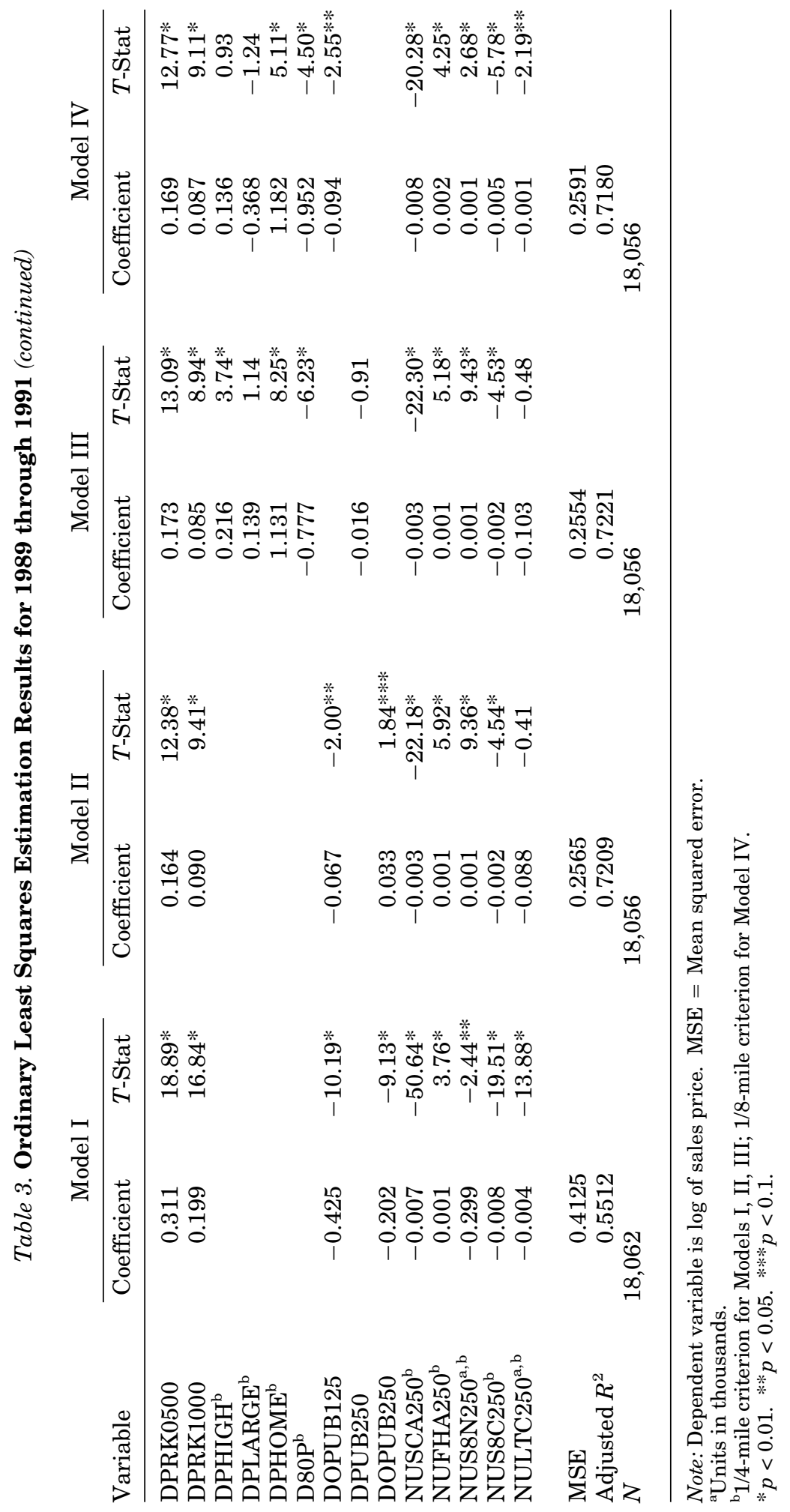


public housing developments, is reduced from -0.43 to -0.07 , and NUS8C250 (Section 8 certificates and vouchers) is reduced from -0.008 to -0.002 . Notably, NUS8N250 (Section 8 New Construction and Rehabilitation) and DOPUB250 (public housing located within a 1/8- to 1/4-mile radius) produce positive signs of coefficients in Model II, as opposed to the negative signs in Model I. Also, NULTC250 (LIHTC) loses statistical significance. These changes in estimation results indicate that the impact of assisted housing on property values is not as critical when the existing neighborhood conditions of assisted housing location are taken into account. Thus, based on Model II, public housing developments, scattered-site public housing, and Section 8 certificates and voucher units have modest to slight negative impacts on property values, while FHA housing and Section 8 New Construction and Rehabilitation exert positive impacts on property values in nearby areas.

Model III includes more detailed characteristics of public housing developments and PHA programs. Contrary to common conceptions, DPHIGH (high-rise developments) and DPLARGE (large developments) do not produce negative signs. However, when a stricter distance criterion of 1/8 mile is included (see Model IV), DPHIGH loses statistical significance and DPLARGE becomes negative but is not significant. In contrast, DPHOME (PHA's homeownership program units) is positive and remains statistically significant in both Model III and Model IV. D80P (public housing developments built since 1980 ) is negative and remains statistically significant in both Models III and IV.

\section{Discussion}

The study results provide valuable comparative information on the impact of assisted housing program types on property values in Philadelphia. According to Model II, when neighborhood characteristics are controlled, both types of public housing (developments and scattered sites) as well as Section 8 rental assistance yield modest to slight negative impacts on property values. In contrast, FHA and Section 8 New Construction and Rehabilitation programs have significant positive effects on property values, as does the PHA homeownership program. The key difference between the FHA and PHA programs and the Section 8 certificates/vouchers and other public housing programs (developments and scattered sites) is that the former are homeownership programs while the latter are rental assistance programs. Section 8 New Construction and Rehabilitation is the only rental housing program with a positive effect on property values (though it is slight), an effect that is significantly reversed when neighborhood control variables are not included, as in Model I. Taken together, these findings suggest that homeownership and 
new construction/rehabilitation programs produce better locational outcomes than rental assistance programs, as indexed by property values.

Consistent with our hypothesis, the Section 8 certificates and vouchers program had a negative market impact, though the effect is very modest (coefficient $=-0.003$ in Model IV). This finding runs counter to the national data on neighborhood characteristics reported by Newman and Schnare (1997) but is consistent with the results of Galster and Tatian (1998), which led us to predict a negative impact on property values. Similarly, the negative effect of scattered-site public housing suggests that it is not just the public housing developments that are problematic for property values but that concentrations of low-density public housing have negative market impacts. While the effect is small, it nevertheless may reflect maintenance-related difficulties; the use of older, rehabilitated structures; and other management issues affecting the Philadelphia Housing Authority.

Interestingly, no statistically significant effects are found for the physical type of public housing developments, be they large developments or high-rise buildings, when the stricter 1/8-mile criterion is applied. If such impacts exist, they are not large enough to be captured by our property sales data. It is also possible that too few sales occurred in areas with large or high-rise public housing to produce reliable estimates. However, public housing built after 1980 does exert a negative impact on property values, as expected. This result is likely related to the stricter eligibility standards (federal preferences) for public housing promulgated in 1980, under which households with very low incomes (the homeless, those paying more than 50 percent of income for rent, and those displaced from or living in substandard housing) are given greater priority for placement in public housing (Epp 1996). According to Epp, from 1981 to 1991, the proportion of very poor households (below 10 percent local median income) in public housing increased eightfold, from 2.5 to 20 percent. Epp also notes that most public housing households now have incomes below 20 percent of local median income. This shift in the demographic composition of public housing residents after 1980 likely exerts a negative impact on nearby property values of newer developments, as indicated by our results.

The Section 8 New Construction and Rehabilitation program, which supports private multifamily or other rental housing, did yield a significant though modest positive effect and so would not support our prediction of no market impact of such programs. Also contrary to our prediction, LIHTC had a significant negative effect on property values in Model IV. These contrasting findings for the publicly assisted private stock may reflect differential siting decisions for 
the programs or differences in management or tenant selection procedures. According to a housing official in Philadelphia (Wilds 1998), that is not a likely explanation. Instead, Wilds posits that the differential effect is likely a result of a lag in the positive impact of such programs on property values. Given that Philadelphia's Section 8 New Construction and Rehabilitation units are from an older program (mostly pre-1985) and that the LIHTC units are from a newer program (mostly post-1987), one might expect the lag effect to produce positive results in the former program before they would appear in the latter. This interpretation would be consistent with the results based on our study period.

This study is limited in that it analyzed data for a single U.S. city and therefore may not be generalizable to other U.S. cities. The available data also did not permit an analysis of price change trends, only a cross-sectional treatment of sales data. This as well as other model specifications could affect results. The study did improve on the literature in providing a comparative framework for assessing the housing market impact of various assisted housing programs. The study also includes neighborhood level control variables, thereby permitting a less biased estimate of the effects of the various housing assistance programs. Although this partially addresses the confounding influence of siting decisions versus program impacts, longitudinal data are necessary to more fully control for preexisting neighborhood conditions. Future research should replicate this study in other localities and might even include national samples to assess how these various programs function in a more diverse set of urban environments.

The study results, because they are taken from a single city, do not permit firm generalizations, but they do suggest a need for continued discussion of several policy considerations. First, the study affirms the value of homeownership programs compared with rental assistance programs in improving communities at the same time that housing opportunities are improved for program participants. However, whether this effect is a function of the differential characteristics of assisted renter versus owner households is not known and deserves further study. Second, the results could be viewed as supportive evidence for the Quality Housing and Work Responsibility Act of 1998, which requires increases in the diversity of residents of public housing through income mixing, targeting based on higher incomes, and the repeal of federal preferences. To the extent that the "built since 1980" variable reflects the added distress created by targeting public housing to the poorer and more at-risk households, the study results support the relaxation of those preferences. Finally, our findings provide support for arguments that the existing system of public and certificate housing creates or contributes to reduced property values, although the modest size of these 
negative effects and their significant reduction when neighborhood characteristics are included suggest that they may be, in part, a function of locational constraints of such housing. Clearly, more temporally sensitive research models are needed, as are studies of the locational choices of certificate and voucher recipients and the siting decisions of local housing authorities.

\section{Conclusion}

Keeping in mind that the study reflects the impacts of programs in a single city, the results suggest that at least in Philadelphia, federally assisted homeownership programs have a more beneficial impact on surrounding neighborhoods than any type of rental assistance program. However, the negative impact of rental assistance programs (Section 8 as well as public housing) on property values is modest when control variables for neighborhood characteristics are included. Public housing preferences since 1980 also appear to have worsened the impact of public housing on surrounding areas. To the extent that neighborhood impacts are important for producing positive outcomes for residents, this finding would lend support to recent proposals intended to diversify the population of public housing residents.

\section{Authors}

Chang-Moo Lee is Senior Fellow at the Wharton Real Estate Center at the University of Pennsylvania. Dennis P. Culhane is an Associate Professor in the School of Social Work at the University of Pennsylvania. Susan M. Wachter is Professor and Chair of the Real Estate Department in the Wharton School at the University of Pennsylvania.

The case study on which this article is based was funded by a grant from the U.S. Department of Housing and Urban Development, Office of Policy Development and Research.

\section{References}

Aaronson, Daniel. 1995. Using Sibling Data to Estimate the Impact of Neighborhoods on Children's Educational Outcomes. Unpublished paper. Northwestern University.

Bailey, Trevor C. 1995. Interactive Spatial Data Analysis. Essex, England: Longman Group.

Carter, William H., Michael H. Schill, and Susan M. Wachter. 1998. Polarisation, Public Housing and Racial Minorities. Urban Studies 35(10):1879-1911. 
Chandler, Mittie O., Virginia O. Benson, and Richard Klein. 1993. The Impact of Public Housing: A New Perspective. Real Estate Issues 18(1):29-32.

DeSalvo, R. W. 1974. Neighborhood Upgrading Effects of Middle-Income Housing Projects in New York City. Journal of Urban Economics 1(3):269-77.

Epp, Gayle. 1996. Emerging Strategies for Revitalizing Public Housing Communities. Housing Policy Debate 7(3):563-88.

Galster, George, and Peter Tatian. 1998. The Property Value Impacts of Neighbors Receiving Housing Subsidies. Paper presented at the Association of Collegiate Schools of Planning Conference, November 5, Pasadena, CA.

Galster, George, and Yolanda Williams. 1994. Dwellings for the Severely Mentally Disabled and Neighborhood Property Values: The Details Matter. Land Economics 70(4):466-77.

Guy, Donald C., John L. Hysom, and Stephen R. Ruth. 1985. The Effect of Subsidized Housing on Values of Adjacent Housing. Journal of the American Real Estate and Urban Economics Association 13(4):378-87.

Newman, Sandra J., and Ann B. Schnare. 1997. “. . . And a Suitable Living Environment": The Failure of Housing Programs to Deliver on Neighborhood Quality. Housing Policy Debate 8(4):703-41.

Nourse, Hugh O. 1963. The Effects of Public Housing on Property Values in St. Louis. Land Economics 52(February):54-65.

Rabiega, William A., Ta-Win Lin, and Linda M. Robinson. 1984. The Property Value Impacts of Public Housing Projects in Low and Moderate Density Residential Neighborhoods. Land Economics 60(2):174-79.

Schafer, Robert. 1972. The Effect of BMIR Housing on Property Values. Land Economics 48(August):262-86.

Schill, Michael, and Susan M. Wachter. 1995. The Spatial Bias of Federal Law and Policy: Concentrated Poverty in Urban America. University of Pennsylvania Law Review 143:1285-1342.

Simons, Robert A., Roberto Quercia, and Ivan Maric. 1998. The Value Impact of New Residential Construction and Neighborhood Disinvestment on Residential Sale Price. Journal of Real Estate Research 15(1/2):147-61.

U.S. Department of Housing and Urban Development. 1997. A Picture of Subsidized Households. World Wide Web page <http://www.huduser.org> (last modified May).

Wilds, Scott. 1998. Personal communication, Philadelphia Mayor's Office of Housing and Community Development, November 11.

Wilson, James Q., and G. L. Kelling. 1982. The Police and Neighborhood Safety. The Atlantic (March 1982):29-38.

Wilson, William J. 1987. The Truly Disadvantaged: The Inner City, the Underclass and Public Policy. Chicago: University of Chicago Press. 
